\title{
REACTION OF R/C SLABS CROSS-SECTIONS TO FIRE Calculation of simplified substitute temperature loads induced by an unsteady heat flow
}

\author{
Robert Kowalski $^{\mathrm{a}}$, Marian Abramowicz ${ }^{\mathrm{b}}$, Paweł Chudzik ${ }^{\mathrm{a}}$ \\ ${ }^{\mathrm{a}}$ WarsawUniversity of Technology, Faculty of Civil Engineering, Poland \\ ${ }^{\mathrm{b}}$ The MainSchool of Fire Service, Faculty of Fire Safety Engineering, Poland
}

\begin{abstract}
An important issue in advanced analysis of reinforced concrete structures exposed to fire is to determine the response of structural elements (cross-sections) to the effect of high temperature. The unsteady heat flow results in a nonlinear temperature distribution. In practical structural calculations performed by simplified computer programs the average temperature value and the appropriate temperature gradient are used. This paper presents substitute values of these parameters and detailed analysis of nonlinear temperature distribution in $20,25,30 \mathrm{~cm}$ thick reinforced concrete slabs exposed to one-sided standard fire.
\end{abstract}

Keywords: structure, reinforced concrete, fire, high temperature, strain

\section{INTRODUCTION}

Thermal actions on structures from fire exposure are classified as accidental actions. In order to perform reliable analysis of complex reinforced concrete structures exposed to fire simplified or advanced computational methods arerecommended (EN 1992-1-2:2004).In advanced computational methods complete thermal and mechanical response of structureunder fire conditionshould be considered.The major issue in analysis of complex, speciallystatically indeterminate structures is to correctly determine the response of structural elements (cross-sections) to the effect of high temperature. Distribution of this parameter caused by unsteady heat flow is non-linear. From an engineering point of view,estimation of strains in these conditions can be a nontrivial, unusually laborious task.

In practical structural calculations performed bysimplified computer programs the average temperature value and the appropriatetemperature gradient can be usedas an input data. Substitute values of these parameters, appropriate for reinforced concrete structures subjected to fire are given in this paper. For this purpose, analysis ofnonlinear temperature distributions in reinforced concrete slabs (walls) with a thicknessvarying from 20 to $30 \mathrm{~cm}$,exposed to one-sided standard fire were performed.Temperature fields were taken from the previous study (Kowalski, 2010)as results of FEM calculations. Specific heat and thermal conductivity of concrete were adopted on the basis of (EN 1992-1-2:2004) for the concrete moisture content 3\%. The heat flux penetrating into the crosssection on the fire exposed surface and the heat flux on the unexposed sidewere determined by using equation given in (EN 1991-1-2:2002). Gas temperature on the heated surface of the slab was adopted as nominal, standard temperature-time curve.Gas temperature on the unheated surface of the slab was assumedas constant value of $20^{\circ} \mathrm{C}$. Time of heating corresponds to common fire resistance of reinforced concrete structures30, 60, 90, 120, 180 and 240 minutes (EN 1992-12:2004).

\section{NONLINEAR TEMPERATURE DISTRIBUTION}

Temperature distribution in 20,25,30 cm thick concrete slabs after 60 and 120 minutesofstandard fire exposure has been depicted inFigure 1 (Kowalski, 2010). 
a)

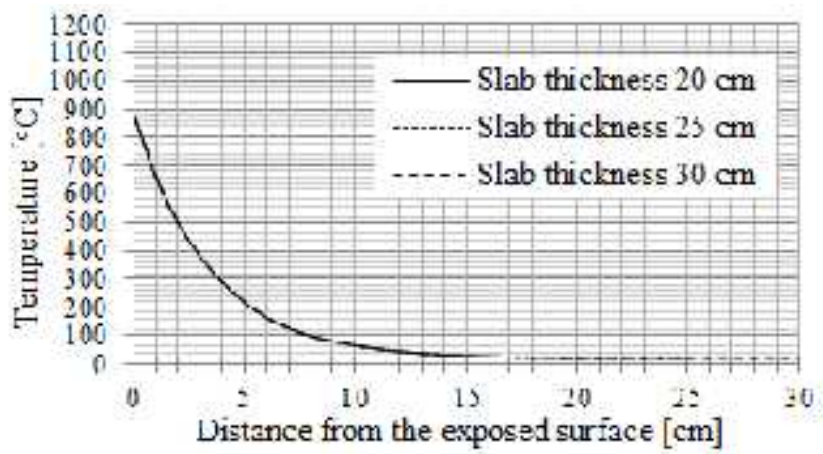

b)

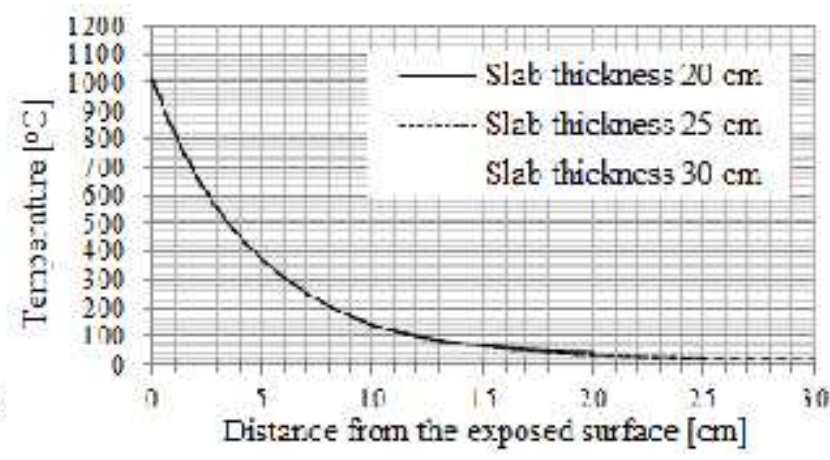

Fig.1 Temperature distribution in 20, 25, $30 \mathrm{~cm}$ thick slab cross-sections exposed to one-sided standard fire fora) 60 minutes, b) 120 minutes(Kowalski, 2010)

It can be observed that the temperature curves for three different slab thicknesses practically overlapeach other showing only slight variations when the fire exposure time exceeds 120minutes.Hence, for a standard slab thickness and atypical fire exposure(important from a practical point of view) temperature values in places where reinforcement could be arranged do not depend on slab thickness.

From a nonlinear temperature distribution curve described by any mathematical equation three separate components can be extracted (Clark at al., 1987):

- anonlinear, so-called "self-equilibrated", described in the latter part of this paper

- alinear, steady

-a linear, symmetric with respect to the central, horizontal axis of the cross-section

The first, nonlinear component has a local effect and does not cause any deformation of the element but only internal stresses (tensile and compressive) in the cross-sections. The remaining two linear componentsdetermine thermal response of structural elements to fire. In statically determinatestructures the linear componentscauseonly deformations (elongation and bending) while in statically indeterminate structures -deformations and occurrence of additional internal forces. The sum of linear components canbe described by a linear function.

\section{EXTRACTION OF THE COMPONENTS OF NONLINEAR TEMPERATURE DISTRIBUTION}

At first, in order to facilitate analysis, nonlinear temperature distribution in slab cross-section (see Fig.1) was approximated by a polynomial function of degree 6 (1), convenient forfurther transformation (integration).

$$
f(x)=A \cdot x^{6}+B \cdot x^{5}+C \cdot x^{4}+D \cdot x^{3}+E \cdot x^{2}+F \cdot x+G
$$

The use of a lower degree polynomial would result inan unsatisfactory convergence with the FEMcalculation particularlyfor shorter heating durationwhereasa polynomialof a higher degree would not significantly improve the accuracy.Coefficients A, B, .., F are numerical constants. The equation (1) canbe expressedas a sum (2a) of linear (2b) and nonlinear (2c)components (Clark at al., 1987).

$$
\begin{gathered}
f(x)=l(x)+r(x) \\
l(x)=H \cdot x+l \\
n(x)=A \cdot x^{6}+B \cdot x^{6}+C \cdot x^{4}+D \cdot x^{3}+E \cdot x^{2}+K \cdot x+L
\end{gathered}
$$


Coefficients $\mathrm{H}, \mathrm{I}, \mathrm{K}, \mathrm{L}$ are unknown variables.

A nonlinear component $\mathrm{n}(\mathrm{x})$ is defined so that the graph of this function is "self-equilibrated" with respect to the horizontal line corresponding to the temperature of $20^{\circ} \mathrm{C}$. This condition is satisfied, when the values of proper definite integrals of nonlinear function $(3,4)$ are equal to zero.

$$
\int_{u}^{h}(n(x)-20) d x=0
$$

The variables $\mathrm{K}, \mathrm{L}$ that define the nonlinear component $(2 \mathrm{c})$ have been calculated by substituting equation (2c) to equations (3) and (4). Then variables H,I that define the linear component (2b) have been calculated as: $H=F-K ; I=G-L$.

Table 1 presents temperature values in the selected sections as results obtained from equation (1, $2 b, 2 c)$.

Table 1 Temperature values in selected cross-sections of $25 \mathrm{~cm}$ thick slab exposed to 60 minutes one-sided standard fire: $\mathrm{x}$-distance from section to the heated surface of element; " $\mathrm{m}(\mathrm{x})$ "-temperature values as results of FEM analysis (Kowalski, 2010); " $\mathrm{f}(\mathrm{x})$ "-temperature values as results of approximation nonlinear temperature distribution by a polynomial function of degree $6(1)$; "l(x)"-temperature values as results of linear component (2b); " $\mathrm{n}(\mathrm{x})$ "-temperature values as results of nonlinear "self-equilibrated" component (2c); " $\Delta$ "-the temperature difference, $\Delta=\mathrm{f}(\mathrm{x})$-m(x)

\begin{tabular}{|c|c|c|c|c|c|c|c|c|c|c|c|}
\hline $\mathrm{x}[\mathrm{cm}]$ & 0 & 2 & 5 & 7 & 10 & 12 & 15 & 17 & 20 & 22 & 25 \\
\hline $\mathrm{m}(\mathrm{x})\left[{ }^{\circ} \mathrm{C}\right]$ & 889.07 & 500.92 & 219.05 & 125.35 & 65.65 & 45.09 & 29.17 & 24.33 & 21.23 & 20.49 & 20.18 \\
\hline $\mathrm{f}(\mathrm{x})\left[{ }^{\circ} \mathrm{C}\right]$ & 886.52 & 503.04 & 216.67 & 128.49 & 65.06 & 44.59 & 28.96 & 24.41 & 21.66 & 20.36 & 20.74 \\
\hline $\mathrm{l}(\mathrm{x})\left[{ }^{\circ} \mathrm{C}\right]$ & 375.16 & 333.83 & 271.85 & 230.52 & 168.54 & 127.21 & 65.22 & 23.90 & -38.09 & -79.41 & -141.40 \\
\hline $\mathrm{n}(\mathrm{x})\left[{ }^{\circ} \mathrm{C}\right]$ & 511.36 & 169.21 & -55.18 & -102.03 & -103.48 & -82.62 & -36.26 & 0.51 & 59.75 & 99.77 & 162.14 \\
\hline$\Delta\left[{ }^{\circ} \mathrm{C}\right]$ & -2.55 & 2.12 & -2.38 & 3.14 & -0.59 & -0.50 & -0.21 & 0.08 & 0.43 & -0.13 & 0.56 \\
\hline$\Delta[\%]$ & 0.3 & 0.4 & 1.1 & 2.5 & 0.9 & 1.1 & 0.7 & 0.3 & 2.0 & 0.6 & 2.8 \\
\hline
\end{tabular}

The results of FEManalysis (Kowalski, 2010) are highly consistent with the temperature values obtained by their approximation by polynomial function of degree 6 and do not differ more than $3 \%$. The accuracy of the polynomial coefficients played an important role during the analysis.

Figure 2 shows representative graphs of nonlinear temperature distribution and its componentsfor $25 \mathrm{~cm}$ thickreinforced concrete slab exposed to one-sided standard firefor 60 minutes.

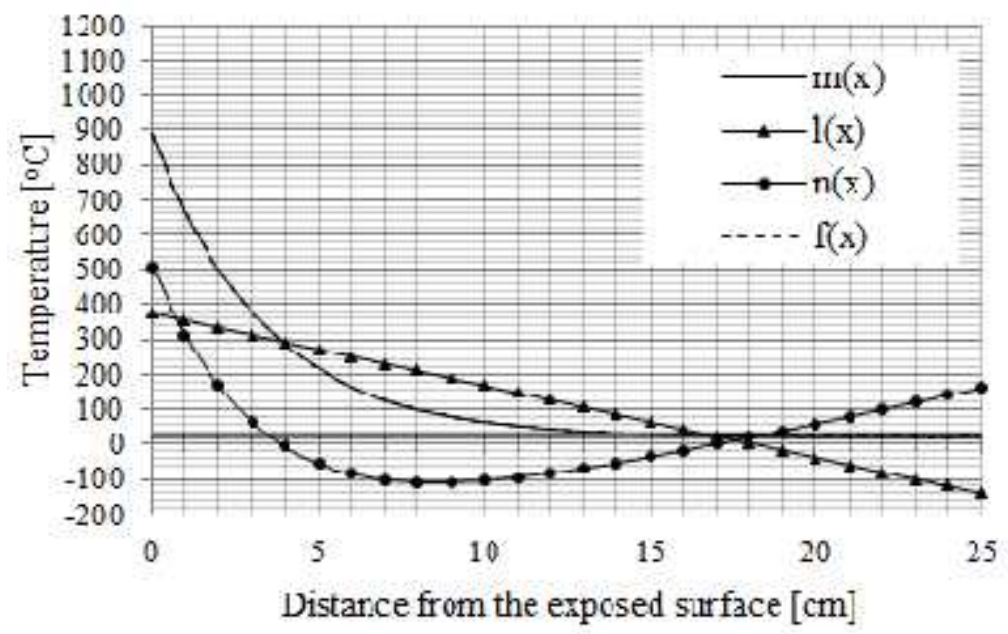


Fig.2Temperature distribution in reinforced concrete $25 \mathrm{~cm}$ thick slab exposed to 60 minutes one-sided standard fire: " $\mathrm{m}(\mathrm{x})$ "'-nonlinear curve of temperature in the considered cross-section based on FEM analysis(Kowalski, 2010); „f(x)”- approximationof FEM results by a polynomial function of degree 6 (1); ,1(x)"- linear component of temperature distribution causes section deformation; „n(x)"-nonlinear "selfequilibrated" component of temperature distribution causesinternal forces; horizontal bold line corresponds to the initial temperature value $\Theta_{0}=20^{\circ} \mathrm{C}$

\section{IMPACT OF HIGH TEMPERATURE ON REINFORCED CONCRETE SLABS}

Similar analysis were performed for all considered slab thicknesses 20, 25, $30 \mathrm{~cm}$ exposed to standard fire on one side for 30, 60, 90, 120, 180 and 240 minutes. The distribution of temperature components in the examined slabs is presented in Figure 1.

a)
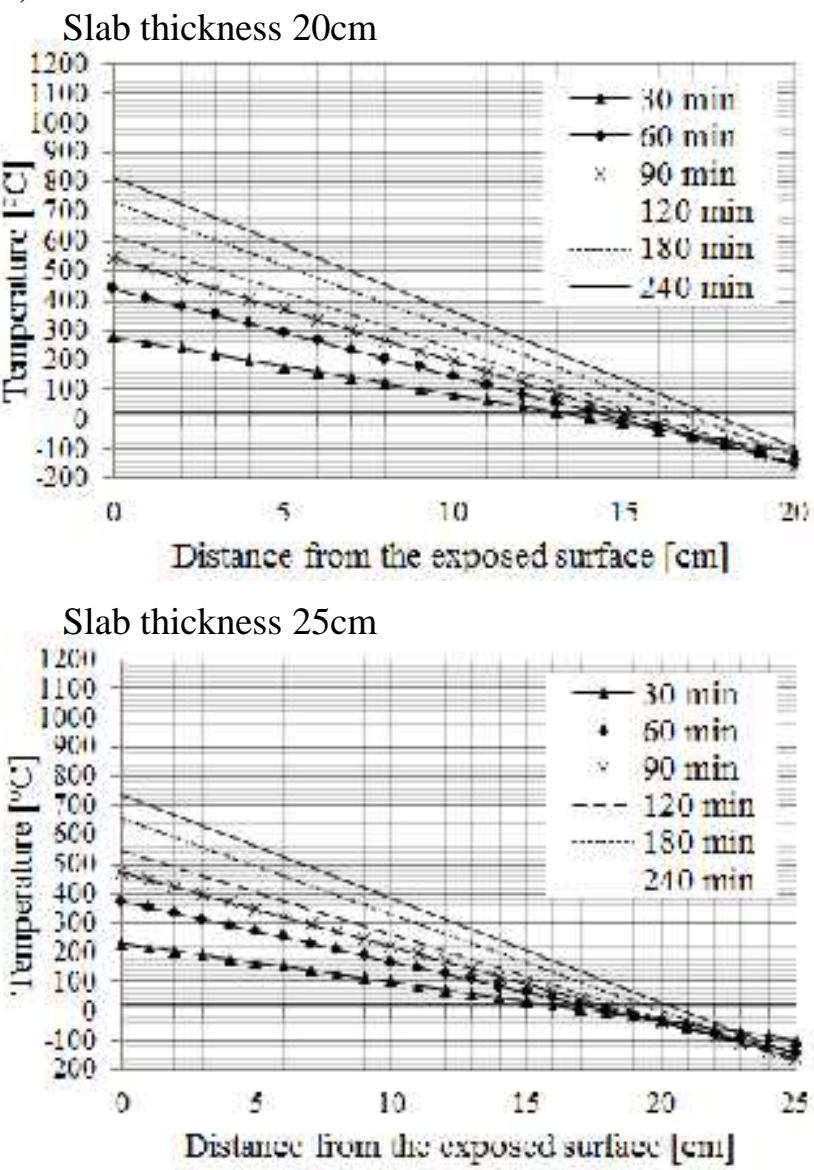

Slab thickness $30 \mathrm{~cm}$

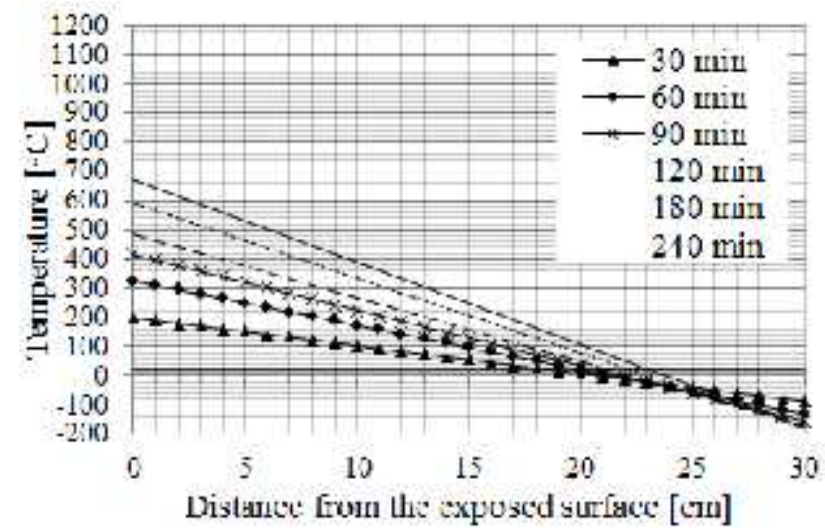

b)
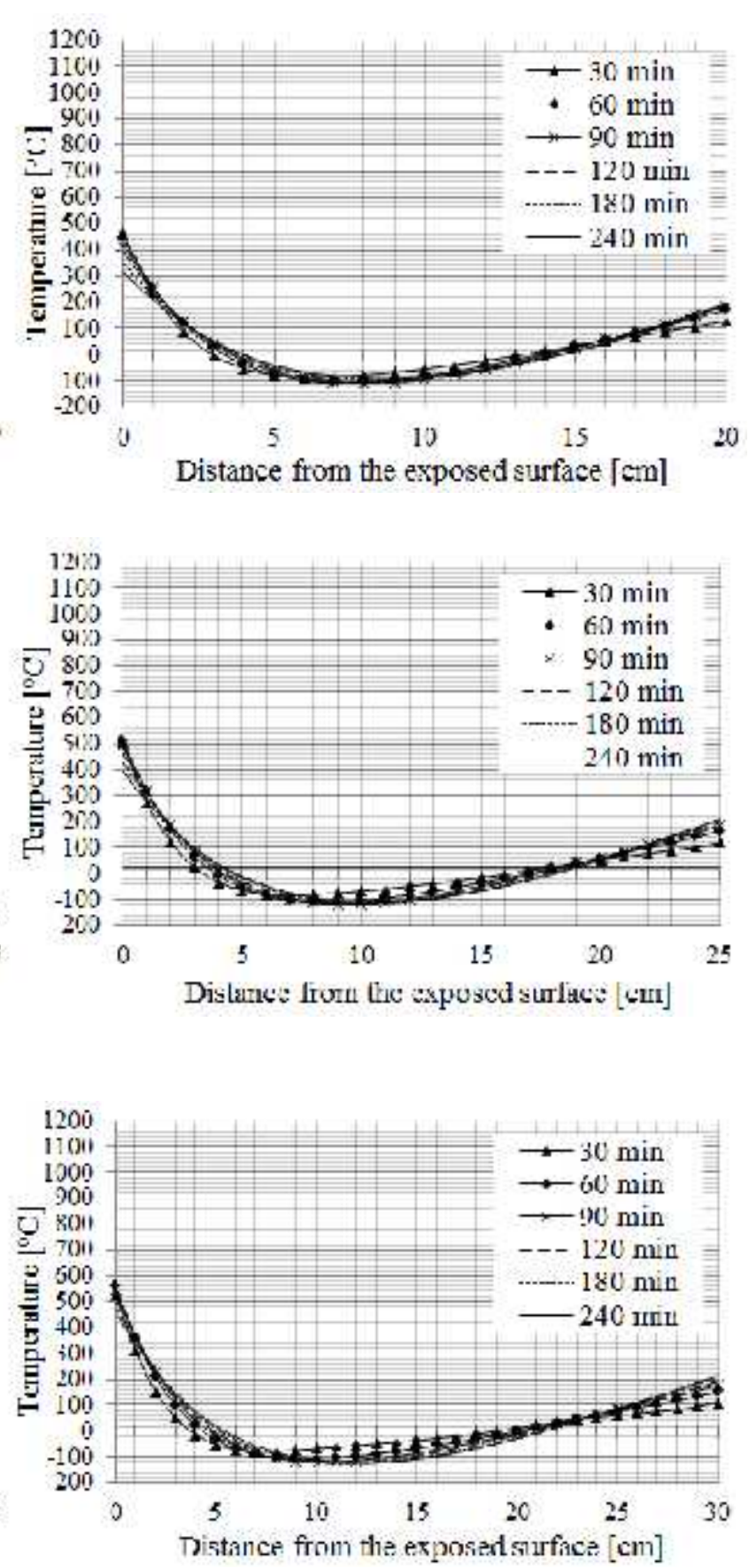

Fig.3Components of nonlinear temperature distribution in $20,25,30 \mathrm{~cm}$ thick reinforced concrete slabs at different timeof standard fire exposure. Column a) linear component, column b) nonlinear "self-equilibrated" component; horizontal bold line corresponds to the initial temperature value $\Theta_{0}=20^{\circ} \mathrm{C}$ 
For each thickness the average temperature value and the corresponding temperature gradient in the cross-section were calculated(Table 2).

Table 2Average temperature value and the appropriate temperature gradient value in $20,25,30 \mathrm{~cm}$ thick reinforced concrete slabs exposed to one-sided standard fire from 30 to 240 minutes. Values calculated on the basis of linear component of temperature distribution $(2 b)$.

\begin{tabular}{|c|c|c|c|c|c|c|c|c|c|c|c|c|}
\hline \multirow{2}{*}{$\begin{array}{l}\text { Time of } \\
\text { fire } \\
\text { exposure }\end{array}$} & \multicolumn{4}{|c|}{ Slab thickness $20 \mathrm{~cm}$} & \multicolumn{4}{|c|}{ Slab thickness $25 \mathrm{~cm}$} & \multicolumn{4}{|c|}{ Slab thickness $30 \mathrm{~cm}$} \\
\hline & $\begin{array}{l}\mathrm{T}_{\max } \\
{\left[{ }^{\circ} \mathrm{C}\right]}\end{array}$ & $\begin{array}{l}\mathrm{T}_{\min } \\
{\left[{ }^{\circ} \mathrm{C}\right]}\end{array}$ & $\begin{array}{c}\mathrm{T}_{\mathrm{av}} \\
{\left[{ }^{\circ} \mathrm{C}\right]}\end{array}$ & $\begin{array}{c}\Delta \mathrm{T} \\
{\left[{ }^{\circ} \mathrm{C}\right]}\end{array}$ & $\begin{array}{l}\mathrm{T}_{\max } \\
{\left[{ }^{\circ} \mathrm{C}\right]}\end{array}$ & $\begin{array}{l}\mathrm{T}_{\min } \\
{\left[{ }^{\circ} \mathrm{C}\right]}\end{array}$ & $\begin{array}{c}\mathrm{T}_{\mathrm{av}} \\
{\left[{ }^{\circ} \mathrm{C}\right]}\end{array}$ & $\begin{array}{c}\Delta \mathrm{T} \\
{\left[{ }^{\circ} \mathrm{C}\right]}\end{array}$ & $\begin{array}{l}\mathrm{T}_{\max } \\
{\left[{ }^{\circ} \mathrm{C}\right]}\end{array}$ & $\begin{array}{l}\mathrm{T}_{\min } \\
{\left[{ }^{\circ} \mathrm{C}\right]}\end{array}$ & $\begin{array}{c}\mathrm{T}_{\mathrm{av}} \\
{\left[{ }^{\circ} \mathrm{C}\right]}\end{array}$ & $\begin{array}{c}\Delta \mathrm{T} \\
{\left[{ }^{\circ} \mathrm{C}\right]}\end{array}$ \\
\hline $30 \mathrm{~min}$ & 277 & -110 & 84 & & 232 & -98 & 67 & 329 & 199 & -87 & 56 & 285 \\
\hline $60 \mathrm{~min}$ & 440 & -148 & 146 & 588 & 375 & 14 & 117 & 517 & 326 & -13 & 97 & 456 \\
\hline $90 \mathrm{~min}$ & 545 & -155 & 195 & 701 & 473 & -16 & 156 & 63 & 416 & -15 & 130 & 571 \\
\hline $120 \mathrm{~min}$ & 623 & -149 & 237 & 772 & 548 & -167 & 190 & 715 & 486 & -169 & 159 & 654 \\
\hline $180 \mathrm{~min}$ & 735 & -123 & 306 & 858 & 658 & -162 & 248 & 820 & 592 & -178 & 207 & 770 \\
\hline $240 \mathrm{~min}$ & 818 & -94 & 362 & 912 & 739 & -147 & 296 & 886 & 672 & -175 & 249 & 847 \\
\hline
\end{tabular}

The nonlinear "self-equilibrated" component causes internal stresses (tensile and compressive) in the cross-sections and does not have a significant impact on the deformations analysis of reinforced concrete elements in fire conditions. Analyzing Figure 3 it can be observed that compressive forces arise on the outer edges of cross-section, while on the inside part of the element tensile forces occur. For the reasons noted above, for practical application in structural fire design of complex reinforced concrete structures it can be assumed that in fire condition slabs are heated evenly and loaded bytemperature gradient. In this case slab deformations can be estimated based on the temperature values from Tab.2 and coefficient of thermal elongation $10^{-5}$ (EN 1992-1-1:2004). For example for a typical $25 \mathrm{~cm}$ thick reinforced concrete slab with aplan dimensions of $30 \times 30 \mathrm{~m}$ total thermal elongation after 60 minutes of standard fire exposure is approximately $3.5 \mathrm{~cm}$. After 120 minutes of heating this value rises to approximately $5.7 \mathrm{~cm}$.According to standards (EN 1992-1-2:2004) in siliceous aggregate concrete elements thermal elongation will reach slightly lower values, $2.7 \mathrm{~cm}$ and $5.1 \mathrm{~cm}$ for 60 and 120 minutes of fire exposure. In practice free thermal elongation of slabs is restrained by vertical members like concrete walls and columns.

It should be noted that estimation of reinforced concrete members deformation under fire condition based on free thermal elongation is appropriate only for the low load level elements, where compressive stress value does not exceed $20 \%$ of concrete strength (Kowalski, 2010). This is applicable for slabs or walls considered in horizontal direction. In case of higher load level, if compressive stress value equals approximately 40-60\% of concrete strength (e.g. columns, walls considered in vertical direction, prestressed concrete elements) load-induced thermal strains (LITS) may occur during the first heating cycle (Khouryat al., 1985) (Mindegujaat al., 2013). In consequence concrete can "give in" to load, and shortening instead of elongation may occur, leading to possible redistribution of internal forces in the structure.

\section{CONCLUSIONS}

In order to perform advanced analysis of complex reinforced concrete structures under fire conditionsit is critical to determine the proper response of structural elements (cross-sections) to high temperature, including deformation caused by nonlinear temperature distribution.

For a practical application, instructural calculations executed bysimplified computer programs the average temperature value and the appropriatetemperature gradient can be usedas an input data. Substitute values of these parameters, applicable for 20,25,30 cm thick reinforced concrete slabs and walls subjected to one-sidedstandard fire are given in this paper.

A nonlinear curve of temperature distributionin reinforced concrete members subjected to fire can beseparated into two independent components, linear and nonlinear, so-called "self-equilibrated".

The nonlinear component has a local effect anddoes not causeany deformation of the element but only internal stresses (tensile and compressive) in the cross-sections. The linear component 
determines thermal response of structural elements to fire. In statically determinatestructures the linear component causes only deformations (elongation and bending), whereas in statically indeterminate structures it can result in additional internal forces occurring in the element.

Knowledge of linear componentof temperature distribution described in this paper allows to estimate deformation and internal forces in reinforced concrete structures under fire conditions. In the proposed simplified calculation individual cross-sections were loaded with average temperature value and appropriate temperature gradient.

\section{REFERENCES}

Clark L.A., Church J.G.,1987.Thermal Curvatures and Strains in Cracked Reinforced Concrete Beams. Proceedings of The Institution of Civil Engineers.Part 2.Research and Theory.Vol. 83, p.197-212.

EN 1991-1-2:2002: Eurocode 1: Actions on structures - Part 1-2: General actions-Actions on structures exposed to fire.CEN. Brussels.

EN 1992-1-1:2004: Eurocode 2: Design of concrete structures - Part 1-1: General rules and rules for buildings.CEN. Brussels.

EN 1992-1-2:2004: Eurocode 2: Design of concrete structures - Part 1-2: General rules - Structural fire design.CEN. Brussels.

Khoury G. A., Grainger B. N., Sullivan P. J. E., 1985.Transient thermal strain of concrete: literature review, conditions within specimen and behavior of individual constituents. Magazine of Concrete Research, Vol. 37, No. 132, s. 131-144.

Kowalski R., 2010.On the Identification of the Reference Isotherm in the Simplified Analysis of R/C Members in Fire.Studies and Researches. Annual Review of Structural Concrete.Vol. 30.Ed. by Politecnico di Milano and Italcementi, pub.by STARRYLINK (Brescia, Italy), p. 281-306.

Kowalski R.,2010.Mechanical properties of concrete subjected to high temperature.Architecture Civil Engineering Environment. Journal of the Silesian University of Technology, Vol. 3, No. 2, p. 61-70.

Mindeguja J.-C., Hager I., Pimienta P., Carre H., La Borderie C., 2013. Parametrical study of transient thermal strain of ordinary and high performance concrete. Cement Concrete Research, Vol. 48, s. 40-52. 